\title{
EROTOLOGII SCINDATE ÎN PROZA LUI DOSTOIEVSKI
}

\author{
Nina CORCINSCHI \\ Institutul de Filologie Română „B. P.-Hasdeu” al MEC
}

\begin{abstract}
Rezumat. O întreprindere exegetică asupra operei lui Dostoievski este în mod necesar o intrare în cele mai nebuloase adâncimi ale finței umane. Este o întâlnire cu o lume asediată de energiile dionisiace, copleșită de zeul dezordinii și al revoltei. Pasionatul, furiosul, extaziatul din proza lui Dostoievski devin cel mai adesea expresii ale experienței erotice. Prin urmare, în romanele scriitorului rus, erotismul și dragostea nu au nici ape limpezi, nici spectre clare. Personajele sale nu ajung la fuziunea în monada, fiind despărțite violent de stihia extatică, exultare și vertij. Dragostea dublă, iubirea contradictorie, iubirea care frizează ura, iubirea care îşi epuizează toate resursele în vârtejul ei necontrolat - sunt câteva reprezentări ale excesului care dau naștere tragediei.
\end{abstract}

Cuvinte cheie: dragoste, hybris, violență, tragedie, pasiune, exultare și vertij.

Abstract. An exegetical undertaking on Dostoevsky's work is necessarily an entrance into the most nebulous depths of the human being. It is an encounter with a world besieged by Dionysian energies, overwhelmed by the god of disorder and revolt. The passionate, the furious, the ecstatic in Dostoevsky's prose most often become expressions of erotic experience. Therefore, in the novels of the Russian writer, eroticism and love have neither clear waters nor clear spectra. His characters do not reach the fusion in the monad, being violently separated by ecstatic element, exultation and vertigo. Dual love, contradictory love, love that curls hatred, love that exhausts all its resources in its uncontrolled whirlwind - these are some representations of the excess that gives rise to tragedy.

Key words: love, hybris, violence, tragedy, passion, exultation and vertigo.

O întreprindere exegetică asupra operei lui Dostoievski este neapărat o intrare în cele mai nebuloase adâncuri ale ființei umane. E întâlnirea cu o lume asediată de energii dionisiace, cotropită de un zeu al dezordinii și revoltei. Berdiaev găsea geniul lui Dostoievski în autenticitatea cu care sunt exprimate în proza sa apocalipticul și nihilismul specifice spiritului rus. În adâncimile sufletului rus, Dostoievski descoperă „o oarecare isterie metafizică”, ,,inclinația către obsesional și posedare"". Patosul rusesc, setea de absolut, revărsările patetice, tendința spre exces, chemarea neantului sunt surprinse cu precizie de seismograf. Naționalul la Dostoievski are mereu și dimensiunea general-

\footnotetext{
${ }^{1}$ N. Berdiaev, Filosofia lui Dostoievski, Iași, Institutul European, 1992, p. 12.
} 
umanului. Scriitorul a coborât în adâncimile ființei umane, descoperind mecanismul complex al confruntării antinomiilor, a forțelor antagonice ale binelui și răului, a atins acele puncte nevralgice, unde frumusețea se îmbină cu diformul, unde sublimul se împletește cu oroarea. Scriitorul a revelat tragedia omului confruntat cu propriii lui demoni interiori, a urmărit mișcarea lui oarbă prin propriile tenebre. Pentru a da expresie limitei ontologice, scriitorul ridică, în romanele sale, condiția umană pe orbitele excesului. De acolo, personajele își dezlănţuie energiile stihiale, pulsiunile necontrolate, care sparg orice contur și formă prestabilită. Prinse în vertij, chemate să răspundă în fața marilor dileme ale existenței, acestea creează spectacolul diformului, ultragiantului, inexplicabilului.

Pătimașul, furibundul, extaticul în proza lui Dostoievski devin cel mai adesea expresii ale trăirii erotice. De aceea, în romanele scriitorului rus erotismul și iubirea nu au nici apele limpezi, nici spectrele clare. Personajele lui nu ating contopirea în monadă a cuplului, despărţindu-i violent stihia extatică, exultanța și vertijul. Iubirea duală, iubirea contradictorie, iubirea care frizează ura, iubirea care-şi epuizează toate resursele în vâlvătaia ei necontrolată - sunt câteva reprezentări ale excesului care dă naștere tragediei.

Iubirea e o sumă de contradicții care determină mișcări imprevizibile ale vieților omenești și duce destine în inexplicabil, în incontrolabil. Romanul care exprimă cel mai complex altitudinile, dar și diformitățile iubirii duale, adâncurile pătimașe ale erosului împărțit este Idiotul. Mai multe forme ale iubirii vor determina fluxurile și refluxurile circuitului afectiv în acest roman: iubirea-compătimire pentru Nastasia Filippovna și iubirea platonică pentru Aglaia a lui Mîșkin, iubirea patimă, mortificatoare a lui Rogojin, iubirea vanitoasă a Aglaiei, pasiunea alienată, ruinătoare a Nastasiei Filippovna etc.

Cea mai coerentă formă a iubirii în roman o ia sentimentul lui Rogojin pentru Nastasia Filippovna. Obsedantă și maladivă, pasiunea lui va lua conturul fatalității și va sfârși în crimă. Personajul este un învins de propria patimă, este instrumentul cu care ,boala iubirii” va avea un rol ucigaș. Acest tip de iubire este intens vehiculat în literatura erotică, prototipul fiind obsesia erotică a Medeei pentru Iason, cu toată recuzita de blasfemii.

Mai dilematică este iubirea-compătimire a prințului Mîșkin. Resorturile acestui sentiment provin din fibra metafizică a personajului. Frumusețea instaurează raporturi intime cu violența și ambele sunt aduse în orizontul suferinței. Prototipul frumuseții este pentru prinț Nastasia Filippovna - o tânără nefericită, care reprezintă în economia romanului femeia fatală pentru ceilalți, dar și pentru propriul ei destin, este ființa dublă, în care rolul călăului și al victimei sunt într-o perpetuă negociere.

Imaginea acestei femei se încheagă din perspectivele tuturor personajelor romanului. Prințul o cunoaște din istorisirile lui Rogojin din tren, apoi portretul ei capătă consistență din intervențiile familiei generalului Epancin, întregite de fotografia primită de „falsul logodnic” Gania. Dacă perspectivele fluctuante 
ale personajelor creează cunoașterea femeii, fotografia scurtcircuitează recunoașterea. Frumusețea acestei femei deține o taină, un mister și este de esență arhetipală. Pentru un ,idiot” ca Mîșkin, în sens de candid, neîntinat, cu o exceptională inteligență a inimii, imaginea din fotografie reprezintă modelul platonician de frumusețe. O vede deosebit de frumoasă. Speră să fie și bună. Așa încât frumusețea ei să poată „salva lumea”. De aici încolo, destinul prințului este pecetluit. Tot ce va face va avea legătură cu prototipul platonician de frumusețe. La care se adaugă un ingredient nou în istoria erotologiilor consacrate, specific prozei lui Dostoievski: compătimirea, sfâssietoarea milă care-i va aduce fatalmente pe ambii într-o iubire blestemată. „Intr-un fel, crede Ion Ianoși, Rogojin o ucide pe Nastasia din pricina lui: dacă, prins în vârtejul rivalităţii celor două femei, ar fi avut tăria să procedeze aşa cum procedase odinioară Nastasia Filippovna cu el, ar fi scăpat-o de la moarte. Dacă..., dar soarta e inexorabilă. Mîşkin o ucide pe Nastasia prin compasiunea lui. El n-ar fi trebuit să cuteze să se atingă de lumea ei sau, intrând în acest univers vrăjit, ar fi trebuit să-1 domine"

Nastasia Filippovna este situată de la bun început în excepționalitate. Este de o „frumusețe orbitoare”, ,,aproape insuportabilă”, cu o alcătuire care încântă și sperie, de o „bizară frumusețe”. E o formă rarisimă de armonie a contrariilor, compusă din umbre și lumini, care timorează, dar și atrage hipnotic. „Pe Dostoievski 1-a chinuit faptul că frumusețea nu înseamnă numai idealul Madonei, dar și al Sodomei. A simțit că în frumusețe există un fundament demonic întunecat"s, scria Berdiaev. Iar o astfel de frumusețe răvășitoare „face tolerabilă o nevoie de dezordine, de violență și de josnicie care e rădăcina iubirii" ${ }^{4}$.

Imaginea din fotografie a Nataliei Filippovna este izbitoare. Datele frumuseții perfecte, aerul ușor de trufie, pasiunea, dar și suferința fac un aliaj, ale cărui irizări de contrarii armonizate nu scapă ochiului atent și „,avid” al prințului. Întrebat de Gania dacă Rogojin s-ar însura cu ea, prințul răspunde în mod providențial: ,-- Cum să-ți spun, de însurat cred că s-ar însura și mâine, numai că n-ar trece o săptămână și s-ar putea s-o și înjunghie"s. Prințul surprinde tocmai dialectica fatală a patimii lui Rogojin - un „temperament frământat de clocotul unor pasiuni mistuitoare", emanând un circuit orb de energii subterane, care scapă controlului conștiinței - cu frumusețea insurgentă, violentă a Nastasiei Filippovna. O astfel de comuniune este imposibilă, frizează delirul, nebunia și moartea. Aceeași inteligență a inimii o are și tânăra

${ }^{2}$ Ion Ianoși, Dostoievski. Tragedia subteranei, Bucureşti, Editura Fundaţiei Culturale Ideea Europeană, 2004, p. 115.

${ }^{3}$ N. Berdiaev, op. cit., p. 37.

${ }^{4}$ Georges Bataille, Erotismul, traducere din franceză de Dan Petrescu, București, Nemira, 2005, p. 294.

F.M. Dostoievski, Idiotul, traducere din rusă de Nicolae D. Gane, București, Editura Adevărul Holding, 2009, p. 47. 
femeie, care înțelege că, preferându-1 pe Rogojin, alege neantul. Pentru ea, acest bărbat semnifică pedeapsa pentru vina de-a fi fost pângărită de Toțchi, reprezintă ghilotina, predestinatul drum spre moarte.

Nastasia Filippovna e personajul feminin de cea mai mare complexitate în romanul Idiotul. Stihialitatea acestei femeie face imposibilă încadrarea ei într-un concept, într-o ontologie coerentă. Până și mintea cea mai vizionară din roman, Mîșkin, n-o poate ajusta într-un tipar: „Dar n-aș ști să spun dacă e bună sau rea la suflet”. Femeia aceasta e o monadă închisă. Pe Rogojin îl fascinează într-un mod fără scăpare. Din momentul în care o întâlnește, viața lui va deveni o cursă în care el e vânătorul obsedat de prada lui. Toțki, care la început o tratează ca pe o distracție ușoară, ajunge să dezvolte o frică de femeia aceasta, devenită insurgentă, vindicativă, cinică, sarcastică și asupra căreia banii lui nu au nicio putere. El se teme de firea ei năvalnică, turbionară, nestăpânită, știe că „Nastasia Filippovna era în stare să se piardă iremediabil și în chipul cel mai oribil, să apuce drumul Siberiei și al ocnei, numai pentru a avea satisfacția de a fi reușit să-și bată joc în voie de omul care-i inspirase o aversiune atât de inumană" ${ }^{\prime \prime}$. Energia vulcanică a acestei femei se concentrează în întunecimea ochilor: „o întunecime profundă și misterioasă sălășluia în adâncul lor ca o enigmă”. Adulată pentru frumusețe, inteligență și bunătate și contestată în egală măsură pentru păcatul de-a fi fost metresa lui Toțki, această femeie devine centrul erotic iradiant al romanului. Rogojin o iubește cu patimă orbitoare, Mîșkin ,ține la ea” din compasiune. În ochii lui, ea trezește idealul platonician de frumusețe, modelul. De la înălțimea spiritului lui Mîșkin această femeie e o altfel de Marie. Dacă Marie, bolnava de ftizie, cu ochii blânzi, ,plini de bunătate și nevinovăție” a fost inocența pângărită, Nastasia Filippovna reprezintă frumusețea maculată. Suferința le-a înnobilat pe ambele. Mila față de bunătatea și candoarea Mariei revine concentric într-o altă formă, a milei față de frumusețea celeilalte femei.

Nastasia Filippovna este încarcerată în sentimentul culpei că a fost întreținută de Toțki. Nimeni și nimic nu poate dizolva acest sentiment tiranic, care domină întreaga conduită morală a personajului. Aversiunea pentru bărbatul care a dezonorat-o este intim legată de pedeapsă, un element esențial în proza lui Dostoievski. Pedeapsa este o continuă autoflagelare. Sunt câteva forme pe care le ia culpabilizarea: 1. prohibirea vieții ei amoroase și respingerea opțiunii salvatoare, adică a căsniciei cu prințul; 2 . confirmarea calomniei plecând cu Rogojin, femeia se situează de partea decăderii și a desfrâului; 3. moartea simbolică. Înainte de-a fi fizică, moartea ei este simbolică, prin alegerea lui Rogojin.

Eroina nu se cruță și nu cruță pe nimeni din scenariul ei dramatic. Negarea de sine este dusă până la autodistrugere. Autoflagelarea ei publică e un exercițiu de harakiri simbolic, în care victima ofensei se sinucide, punându-

\footnotetext{
${ }^{6}$ Ibidem, p. 57.
} 
și fapta pe conștiințta agresorului ei. Această subtilă dialectică a contrariilor, sadomasochismul moral al personajului sunt cu neputință de înțeles de o minte maniheistă, cum e cea a Aglaiei. „Ah, poate că n-ai să înţelegi toate acestea, Aglaia! Știi că, în conștiința dezonoarei care o chinuiește neîncetat, ea găsește poate o anumită satisfacție, groaznică și nefirească, ca un fel de răzbunare împotriva cuiva?"ๆ. Viața Nastasiei Filippovna se desfăşoară mereu pe muchia excesului, în zodia fatalității. Pedeapsa și autopedeapsa sunt jaloanele esențiale ale comportării sale. Toțki, Gania și Rogojin sunt proiecția negativă a umanului, care provoacă răzbunarea, pedepsirea răului. Mîșkin, Katia, Aglaia o alcătuiesc pe cea pozitivă, care suscită culpa și autopedepsirea păcătoasei. Ambele atitudini sunt generatoare de dramă. Ziua când împlinește douăzeci și cinci de ani de la naștere e și ziua procesului, care îi aduce la „banca acuzaților” pe toți cei care i-au malformat destinul. Femeia îi pune pe vinovați față în față cu trecutul ei, îi pedepsește denunțându-i și se pedepsește într-un mod bizar, în logica celor pe care i-a condamnat, alegând destinul de femeie „cumpărată”. Opțiunea Nastasiei Filippovna nu se datorează faptului că le-ar da dreptate, dar, ca o eroină a tragediilor grecești, femeia se consideră pângărită pentru totdeauna de faptele lor. Condiția de amantă a lui Toțki este stigmatul ei de neșters. E o fatalitate care o va urmări până la moarte. În lumina perfecțiunii lui Mîșkin, a imaginii imaculate a Aglaiei, ,vina” ei strălucește cu forță sporită. Ea se simte pângărită, nedemnă, pierdută, ,ființa cea mai decăzută, cea mai vicioasă din lume” și „victimă a unui ultragiu, ea este o handicapată în raport cu propria sa perfecțiune"

Valeriu Cristea emite o observație esențială despre raportul arhetipal al lui Mîșkin cu Nastasia Filippovna9'. Prima întâlnire a prințului cu tânăra este de natură platoniciană. Ea trezește în el reverberația arhetipului feminin. Întrebat de Nastasia Filippovna de unde o recunoaște, Mîșkin îi răspunde că din fotografie, dar și dintr-o proiecție vizionară: ,- Dar cum m-ai recunoscut? - Pentru că mai înainte văzusem portretul dumitale și [...] ... Și, mai ce? - Și pentru că erai întocmai aşa cum mi te-am închipuit... mi se pare și mie că te-am mai văzut și altă dată... - Unde? Unde? - Ochii dumitale îmi par așa de cunoscuți..., dar nu, e cu neputință! Am spus-o într-o doară, fără să mă gândesc... N-am locuit niciodată la Petersburg... Poate, în vis"”10.

Ochii femeii deșteaptă în el reprezentarea modelului originar. Adică spiritul ei, acea frumusețe care poate salva lumea. Dintre toți admiratorii Nastasiei Filippovna, Mîșkin este singurul a cărui privire poposește asupra spiritului, nu asupra cărnii. Mîșkin privește lumea platonician, cu ochii nostalgici după puritatea și frumusețea dintâi. Prin aceste filtre aperceptive sunt trecuți toți oamenii cu care interacționează prințul. El însuși nu este

\footnotetext{
${ }^{7}$ Ibidem, p. 142.

${ }^{8}$ V. Cristea, Dicționarul personajelor lui Dostoievski, Iași, Polirom, 2007, p. 66.

9 Ibidem, p. 478.

${ }^{10}$ F.M. Dostoievski, op. cit., p. 137.
} 
capabil de aventurile cărnii, deoarece este bolnav. Un bolnav de azur, un idealist, care în lumea profană este văzut drept idiot, adică un inadaptat. Puterea lui stă în spirit. Mîșkin este un povestitor de vocație. El seduce și convinge prin povestire, adică prin înălțimea spiritului, la care se adaugă și blândețea inimii. Toți cei pe care-i întâlnește, își manifestă inițial scepticismul, după care neapărat urmează adeziunea lor empatică.

Iubirea prințului pentru Nastasia Filippovna nu conține dorință erotică, foamea de trup, ci tendinţă sacrificială de a salva frumusețea înnobilată prin suferință. Mîșkin o iubește pe Nastasia Filippovna cu o iubire-compătimire care, în accepție creștină, presupune suferință de dragul aproapelui. Erich Fromm o numește ,iubire fraternă”, considerând-o cea mai profundă formă a iubirii, ,care stă la baza tuturor tipurilor de iubire"11. Pentru Dostoievski, acest tip de iubire este unul fondator și generos, de la iubirea-compasiune pornește acceptarea și asumarea celuilalt ca un egal al tău. Compasiunea pentru Nastasia Filippovna este mai mare decât iubirea lui Mîșkin pentru Aglaia. Pus să aleagă între cele două femei, Mîșkin sacrifică iubirea în numele compasiunii. „, - Dar cum e cu putință? E atât de... nefericită!”, îi reproșează Aglaiei cruzimea cu care o tratează aceasta pe rivala sa.

Spre deosebire de Mîșkin, Rogojin o iubește pe Nastasia Filippovna cu o patimă fatală. Nimic din ce face femeia iubită nu-i alterează sentimentele. Ştie că e preferat ca instrument de autoflagelare, că inima acestei femei nu-i va aparține niciodată, că e o dragoste imposibilă, dar destinul acestei iubiri e pecetluit. Întreaga lui ființă e ținută în cumpănă de obsesia erotică. Discontinuitatea dintre ființa lui și a ei, marele clivaj ontologic poate fi abolit doar prin moarte. Iubirea lui pune în joc violența, care tulbură temeiurile unei lumi încremenite în propria ei inerție. Violența împinge în exces ordinea lumii, îi perturbă contururile. Prin violență, lumea exterioară devine o reflectare a infernului interior. Devine o intrare în anticamera continuității pe care o oferă până la capăt și în mod plenar doar moartea. „Excesul, scrie misticul Bataille, luminează sensul mișcării. Dar pentru noi nu-i decât un semn îngrozitor, amintindu-ne necontenit că moartea, ruptură a acestei discontinuități individuale de care ne tintuiește angoasa, ni se propune nouă ca un adevăr mai iminent decât viața" ${ }^{12}$. Violența și excesul alcătuiesc stihia care-i cuprinde pe Rogojin și Nastasia Filippovna. Ambele personaje încarcă de tensiune spațiul în care își fac apariția. Aerul din preajma lor se înăsprește, devine amenințător, vestește furtunile scandalului. Mișcările ambilor sunt spasmotice, gesturile lor sunt excesive, excentrice, fataliste, conțin amenințarea nelipsită totuși de o doză de grandoare și sublim. Secvența în care Nastasia Filippovna aruncă pachetul cu bani în foc, pentru a-l provoca pe Gania să se arunce după ei e un spectacol al grandorii dionisiace. Fervoarea

${ }^{11}$ Erich Fromm, Arta de a iubi, traducere din engleză de Ruxandra Vișan, București, Editura Trei, 2016, p. 64.

${ }^{12}$ G. Bataille, op. cit., p. 31. 
dionisiacă, incandescența spiritului, căutarea hybrisului sunt atribute care-i unesc pe Rogojin și Nastasia Filippovna. Ambii trăiesc într-un registru paroxistic. „Crăiasă, adevărată crăiasă!”, exultă bărbatul la văzul acestui spectacol incendiar. „E de-a noastră, așa suntem noi, cei din tagma noastră! strigă el în neștire. Ați văzut, șnapanilor? Strașnic! Care dintre voi ar fi în stare să facă așa ceva, ai?"13. Întrebarea lui Rogojin e cât se poate de legitimă, personajul confirmând cu mândrie asumată excepționalitatea tagmei sale.

Frumusețea Nastasiei Filippovna provoacă o dezordine violentă în circuitul de energii al universului romanesc. „O astfel de frumusețe ar putea să răstoarne lumea!" - Adelaida formulează, de fapt, prin această apreciere, rolul dezechilibrant al frumuseții protagonistei. În Aglaia, rivala sa, Nastasia Filippovna descoperă propria ei perfecțiune de dinaintea căderii, candoarea pierdută a frumuseții: „Dumneata ești inocența întruchipată și tocmai această inocență este însăși perfecțiunea dumitale". Căutarea candorii, restabilirea puritătii unei lumi căzute în derizoriu sunt năzuințele platoniciene care-i apropie pe Mîșkin și pe Nastasia Filippovna. Ambii privesc dincolo de contingent, căutând să distingă contururile dintâi ale avatarului desăvârșit, năzuind să conserve ceva din ingenuitatea și puritatea frumuseții.

Aflată între proiecția ei ideală și copia palidă a acesteia, Nastasia Filippovna este un personaj în criză perpetuă. Prezența ei orbitoare stărnește fascinație și atracții irezistibile. Lui Mîșkin îi trezește nostalgia perfecțiunei platoniciene și compătimirea infinită pentru frumusețea ei rănită. Dar și spaima de adâncimile ei dionisiace. Pe Rogojin îl subjugă fulgerător, cu un erotism al voluptății, din prima clipă pentru toată viața. Pe generalul Epancin îl tulbură, acesta dăruindu-i un colier scump de perle, pe Gania îl îmbolnăvește de ideea de a se căpătui printr-un mariaj cu ea. Toate personajele sunt legate prin diferite fire de tensiune de ființa ei. Fiind un personaj excepțional, ea nu se poate pierde în rutina existenței. Nastasia Filippovna iese din orice conventii. Iubirea demonică, terifiantă a lui Rogojin vine ca o pedeapsă a providentei pentru natura ei stricată, resimțită ca stricată, adică deviată de la linia firească a destinului. Ritualul pedepsirii nu se poate împlini decât în moarte. Prin moartea ei, se descoperă acea dimensiune a sacrului care, în înțelesul pe care-l dă Bataille, este tocmai „continuitatea ființei revelată celor ce-și fixează atenția, într-un rit solemn, asupra morții unei ființe discontinue. Din pricina morții violente, se petrece o ruptură în discontinuitatea unei ființe: ceea ce subzistă și, în liniștea ce se lasă, este resimțit de spiritele neliniștite, este continuitatea ființei, căreia victima îi este redată" ${ }^{\prime 1}$. Scena de după omor capătă proporții metafizice, de ritual sacramental, care duce iubirea dincolo, în infinit, pentru a aboli pentru totdeauna chinuitoarea discontinuitate a fiintei: „Doborât de oboseală şi de deznădejde, prinţul îşi lăsă capul pe pernă, lipindu-şi faţa de

\footnotetext{
${ }^{13}$ F.M. Dostoievski, op. cit., p. 225.

${ }^{14}$ G. Bataille, op. cit., pp. 33-34.
} 
chipul palid şi nemişcat al lui Rogojin; lacrimile îi curgeau, prelingându-se pe obrazul lui Rogojin; dar poate că nici nu-şi mai simţea propriile lacrimi, nemaiavând de fapt nici el conştiinţa lucrurilor..."15.

Iubirea, în opera lui Dostoievski, iese din erotologiile ei consacrate; îi lipsește unitatea netedă, este scindată și pătrunsă de tragism. Dezagregarea temeliilor spirituale ale omului, dedublarea, polarizarea conștiinței pulverizează sentimentul amoros în secvențe contradictorii, disonante. Pierzându-și centrul iradiant, pasiunea intră în criză, se alienează. Aducerea iubirii-pasiune și a iubirii-compătimire într-o paradigmă creștină, a iubirii christice, este soluția sugerată de creația lui Dostoievski, după cum arată şi Berdiaev: „Pasiunea şi mila pentru cel iubit sunt întru totul drepte şi justificate. Însă aceste elemente trebuie să fie luminate de întrevederea alterego-ului în Dumnezeu, de contopirea întru Dumnezeu cu alt eu"16. Pentru că iubirea adevărată, în accepția marelui scriitor, este un logos religios, un logos despre Dumnezeu. Despre eternitatea din ființa umană.

\section{Referințe bibliografice:}

1. DOSTOIEVSKI, F.M. Idiotul, traducere din rusă de Nicolae D. Gane, București: Editura Adevărul Holding, 2009.

2. IANOȘI, I. Dostoievski. Tragedia subteranei, Bucureşti: Editura Fundaţiei Culturale Ideea Europeană, 2004.

3. CRISTEA, V. Dicționarul personajelor lui Dostoievski, Iași, Polirom, 2007.

4. BATAILLE, G. Erotismul, traducere din franceză de Dan Petrescu, București: Nemira, 2005.

5. FROMM, E. Arta de a iubi, traducere din engleză de Ruxandra Vișan, București: Editura Trei, 2006.

6. BERDIAEV, N. Filosofia lui Dostoievski, Iași: Institutul European, 1992).

Notă: Articolul a fost realizat în cadrul proiectului de cercetare 20.80009.1606.03 Contexte socioculturale autohtone şi interconexiuni europene în creaţia populară şi literatura cultă din Basarabia (sec. XIX până în prezent), Institutul de Filologie Română „B. P.-Hasdeu” al MEC.

${ }_{16}^{15}$ F.M. Dostoievski, op. cit., p. 359.

${ }^{16}$ N. Berdiaev, op. cit., p. 82. 